\title{
Formation of high nuclearity mixed-valent polyoxovanadates in the presence of copper amine complexes
}

\author{
JENCY THOMAS, ${ }^{\mathrm{a}}$ SANJEEV SHARMA, ${ }^{\mathrm{a}} \mathrm{S}$ E LOFLAND, ${ }^{\mathrm{b}} \mathrm{K}$ V RAMANUJACHARY ${ }^{\mathrm{b}}$ \\ and A RAMANAN ${ }^{\mathrm{a}, *}$ \\ ${ }^{a}$ Department of Chemistry, Indian Institute of Technology, Delhi, New Delhi 110016 \\ ${ }^{b}$ Department of Chemistry and Physics, Center for Materials Research and Education, Rowan University, \\ 201 Mullica Hill Road, Glassboro, NJ 08028, USA \\ e-mail: aramanan@chemistry.iitd.ac.in
}

\begin{abstract}
Two new Müller-type clusters, a one-dimensional solid $\left\{\mathrm{Cu}(\text { en })_{2}\right\}_{4}\left[\mathrm{Cl} \subset \mathrm{V}_{15} \mathrm{O}_{36}\right] \cdot 12 \mathrm{H}_{2} \mathrm{O} \mathbf{1}$, and a three-dimensional solid $\left\{\mathrm{Cu}(p n)_{2}\right\}_{4}\left[\mathrm{Cl} \subset \mathrm{V}_{18} \mathrm{O}_{42}\right] \cdot 12 \mathrm{H}_{2} \mathrm{O} 2$, have been synthesised by employing identical hydrothermal conditions except varying the nature of organic diamine. 1 crystallised in a chiral space group $P 2{ }_{1} 2_{1} 2_{1}$ with $a=12 \cdot 757(1), b=18 \cdot 927(2)$ and $c=28 \cdot 590(3) \AA$, and $Z=4.2$ crystallised in a tetragonal system with space group $P 4 / n n c, a=15 \cdot 113(1)$ and $c=18 \cdot 542(3) \AA$, and $Z=2$. Mixed-valent vanadium ions in structures 1 and 2 have been established both by magnetisation and bond-length bondvalence measurements. Chemistry of formation of high nuclearity polyoxovanadate clusters is discussed.
\end{abstract}

Keywords. Müller-type clusters; polyoxovanadate; copper amine complex; magnetism, hydrothermal conditions.

\section{Introduction}

Polyoxovanadate (POV) cluster based solids are attractive inorganic materials owing to their structural versatility and potential applications in the areas of catalysis, magnetism, medicine etc. ${ }^{1-3} \mathrm{~A}$ range of soluble nano-size vanadium oxide cluster anions formed in the aqueous solution can be stabilised as salts or composite solids by suitable choice of structure directing organic cations or metal complexes. ${ }^{4-6}$ An examination of the crystallographic database (ICSD and CSD) suggests that only a very few high nuclearity clusters, $\left[\mathrm{V}_{x} \mathrm{O}_{y}\right]^{n-}$ with $x>15$ have been structurally characterised (figure 1). It was also observed that such clusters are invariably stabilised from solution containing substantial concentration of lower valent vanadium ions (3+ and 4+). Müller and his group assembled several cage structures $\left[\mathrm{V}_{15} \mathrm{O}_{36}\right]^{5-}$, $\left[\mathrm{V}_{16} \mathrm{O}_{38}\right]^{7-},\left[\mathrm{V}_{18} \mathrm{O}_{42}\right]^{12-},\left[\mathrm{V}_{19} \mathrm{O}_{45}\right]^{9-}$ and $\left[\mathrm{V}_{34} \mathrm{O}_{82}\right]^{10-}$ in which anions are encapsulated inside the cavity of these spherical clusters. ${ }^{7}$ The sizes of the anions $\left(\mathrm{NO}_{3}^{-}, \mathrm{Cl}^{-}, \mathrm{Br}^{-}, \mathrm{SCN}^{-}\right)$appear to dictate the structure and geometry of these solids. Other anions like formate and acetate invariably derivatise the vanadate group and occur on the surface of the cluster anions. A few more groups are also successful in crystallis-

Dedicated to Prof J Gopalakrishnan on his 62nd birthday *For correspondence ing POV clusters wherein $\mathrm{V}>15 .{ }^{8-11}$ Hydrothermal reactions are popular soft chemistry routes to synthesise such solids. Recently, our group has been involved in rationalising critical chemistry issues involved in controlling the reaction and hence the structure of polyoxometalates under hydrothermal condition, even though such reactions are commonly referred as "black-box" in nature. ${ }^{12}$ During our attempts to identify the phases formed in the presence of copper amine complexes, we isolated two mixedvalent microporous solids: $\quad\left\{\mathrm{Cu}(e n)_{2}\right\}_{4}[\mathrm{Cl} \subset$ $\left.\mathrm{V}_{15} \mathrm{O}_{36}\right] \cdot 12 \mathrm{H}_{2} \mathrm{O}(\mathbf{1})$ and a three-dimensional $\left\{\mathrm{Cu}(p n)_{2}\right\}_{4}$

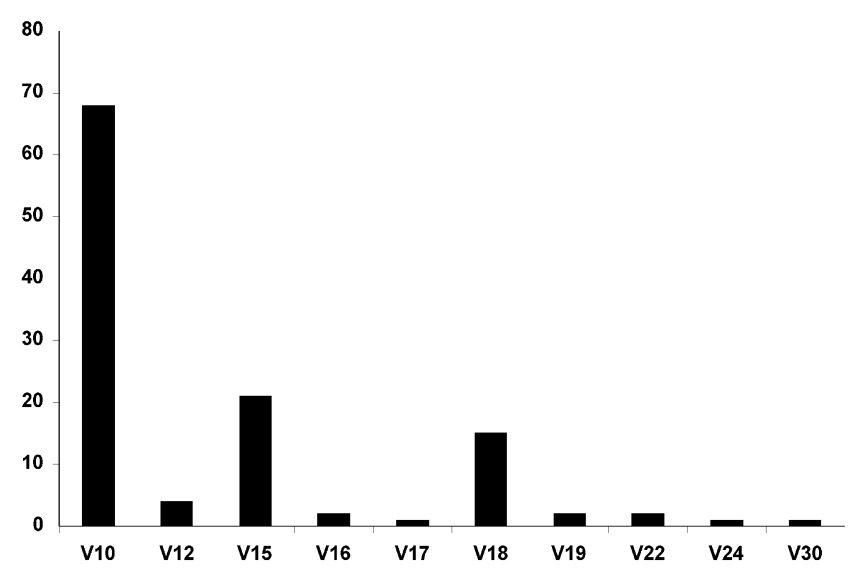

Figure 1. An overview of high nuclearity polyoxovanadates. 
Table 1. Single crystal and experimental data for $\mathbf{1}$ and 2.

\begin{tabular}{|c|c|c|}
\hline Formula & {$\left[\mathrm{Cu}(\mathrm{e} n)_{2}\right]_{4}\left[\mathrm{Cl} \subset \mathrm{V}_{15} \mathrm{O}_{36}\right] \cdot 12 \mathrm{H}_{2} \mathrm{O} 2$} & {$\left[\mathrm{Cu}(p n)_{2}\right]_{4}\left[\mathrm{Cl} \subset \mathrm{V}_{18} \mathrm{O}_{42}\right] \cdot 12 \mathrm{H}_{2} \mathrm{O} 2$} \\
\hline Space group & $P 2_{1} 2_{1} 2_{1}$ & $P 4 / n n c$ \\
\hline$a(\AA)$ & $12 \cdot 757(1)$ & $15 \cdot 113(1)$ \\
\hline$b(\AA)$ & $18 \cdot 927(2)$ & $15 \cdot 113(1)$ \\
\hline$c(\AA)$ & $28 \cdot 590(3)$ & $18 \cdot 542(3)$ \\
\hline$V\left(\AA^{3}\right)$ & $6903 \cdot 3(1)$ & $4235 \cdot 5(8)$ \\
\hline$Z$ & 4 & 2 \\
\hline Molecular weight (g) & $2272 \cdot 43$ & $2687 \cdot 61$ \\
\hline$d_{\text {calc }}\left(\mathrm{g} \cdot \mathrm{cm}^{-3}\right)$ & $2 \cdot 163$ & $2 \cdot 089$ \\
\hline$\mu_{\mathrm{MoK} \alpha}\left(\mathrm{cm}^{-1}\right)$ & $3 \cdot 270$ & $2 \cdot 993$ \\
\hline Diffractometer & Bruker Smart Apex CCD & Bruker Smart Apex CCD \\
\hline Radiation & MoK $\alpha$ & $\operatorname{MoK} \alpha$ \\
\hline$T(\mathrm{~K})$ & $273(2)$ & $273(2)$ \\
\hline Crystal size (mm) & $0.52 \times 0.23 \times 0.13$ & $0.42 \times 0.22 \times 0.16$ \\
\hline Theta range (deg) & $2 \cdot 27-56 \cdot 60$ & $2 \cdot 27-51 \cdot 00$ \\
\hline No. of measured reflections & 62300 & 38425 \\
\hline No. of unique reflection & 9352 & 1985 \\
\hline No. of observed reflections $(I>2 \sigma I)$ & 12359 & 1703 \\
\hline No. of refined parameters & 933 & 141 \\
\hline$R_{1}(I>2 \sigma I)$ & $0 \cdot 0757$ & $0 \cdot 0672$ \\
\hline$W R_{2}($ all $)$ & $0 \cdot 1585$ & $0 \cdot 1534$ \\
\hline $\operatorname{Min} / \max \Delta \rho, c ̧ \cdot \AA^{-3}$ & $-0.838 / 1 \cdot 495$ & $-0.631 / 0 \cdot 765$ \\
\hline CCDC No. & 284863 & 284864 \\
\hline
\end{tabular}

$\left[\mathrm{Cl} \subset \mathrm{V}_{18} \mathrm{O}_{42}\right] \cdot 12 \mathrm{H}_{2} \mathrm{O}$ (2) employing identical reaction conditions except varying the nature of the amine. This paper reports synthesis, structure and magnetic properties of these solids.

\section{Synthesis}

Vanadium pentoxide $\left(\mathrm{V}_{2} \mathrm{O}_{5}\right)$, cupric chloride $\left(\mathrm{CuCl}_{2}\right.$. $2 \mathrm{H}_{2} \mathrm{O}$ ), ethylenediamine (en) and 1,2-diaminopropane (pn) were obtained from Aldrich. All reactions were carried out in teflon-lined stainless steel containers under autogeneous pressure. In a typical synthesis $\mathrm{V}_{2} \mathrm{O}_{5}, \mathrm{CuCl}_{2} \cdot 2 \mathrm{H}_{2} \mathrm{O}$, organic base and distilled water were taken together in the molar ratio 1:1:5.5:1666. The reactants were sealed into a $15 \mathrm{ml}$ teflon-lined acid digestion reactor and heated at $150^{\circ} \mathrm{C}$ for $65 \mathrm{~h}$ and then cooled to room temperature. The resulting products were washed with water, acetone and allowed to dry in air.

\section{Characterisation}

FTIR spectra were recorded on $\mathrm{KBr}$ pellets using a Nicolet 5DX spectrophotometer. TG/DT analysis was carried out using a Perkin-Elmer TGA7 system on well-ground samples in flowing nitrogen atmosphere with a heating rate of $10^{\circ} \mathrm{C} / \mathrm{min}$. The magneti- sation was measured at temperatures ranging from 5 to $300 \mathrm{~K}$, in applied fields of up to 50000 e with a quantum design physical properties measurement system. Corrections due to the diamagnetism of the sample holder have been applied to the data. Structures of $\mathbf{1}$ and $\mathbf{2}$ were determined using single crystal $\mathrm{X}$-ray diffraction. Intensity data collection was carried out on a Bruker Smart Apex CCD diffractometer with a MoK $\alpha$ sealed tube at room temperature. Crystal structures were solved by direct methods using the SHELXTL package. Semi-empirical absorption correction was applied using the SADABS program. The vanadium atoms were first located and then the remaining atoms were deduced from subsequent difference Fourier syntheses. $\mathrm{H}$ atoms were located using geometrical constraints. All atoms except $\mathrm{H}$ were refined anisotropically. Crystal and experimental data are provided in table 1.

\section{Results and discussion}

TGA and DTA curves for $\mathbf{1}$ and $\mathbf{2}$ are shown in figure 2. The weight loss in the lower temperature region can be attributed to the removal of lattice water molecules. The elimination of organic occurred in a broad step; in both the cases the composition derived from TGA agreed reasonably with those ob- 

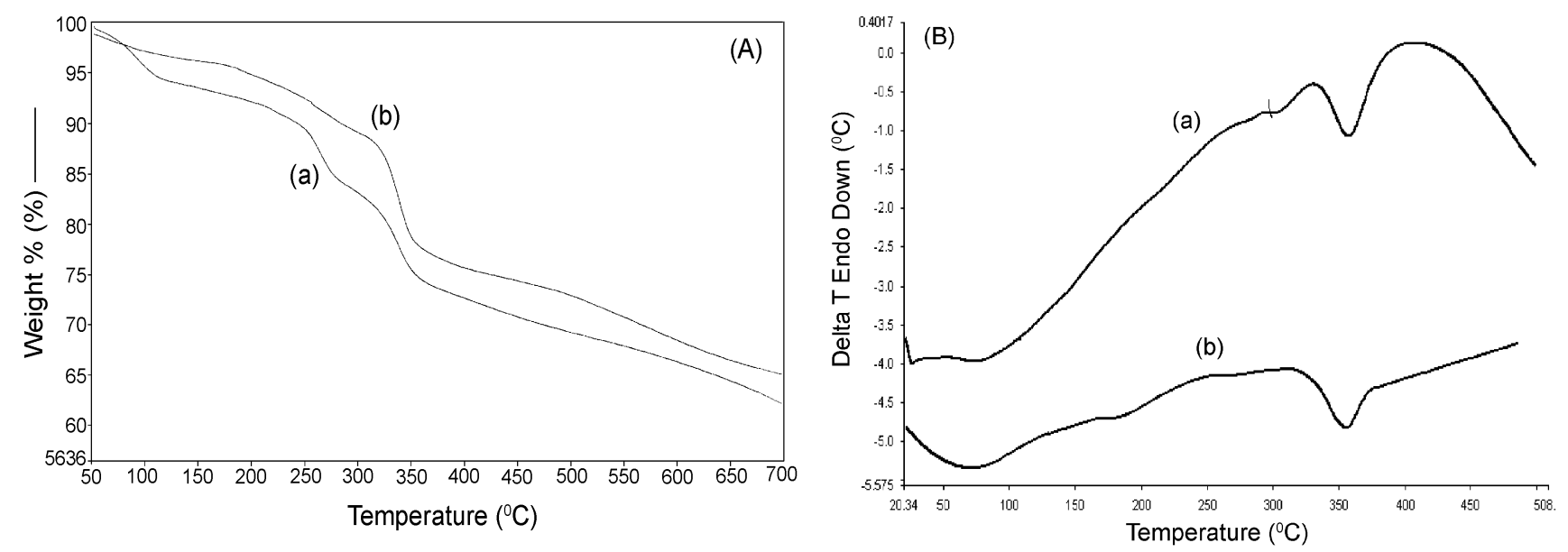

Figure 2. TGA (A) and DTA (B) curves for (a) 1 and (b) 2.

(a)

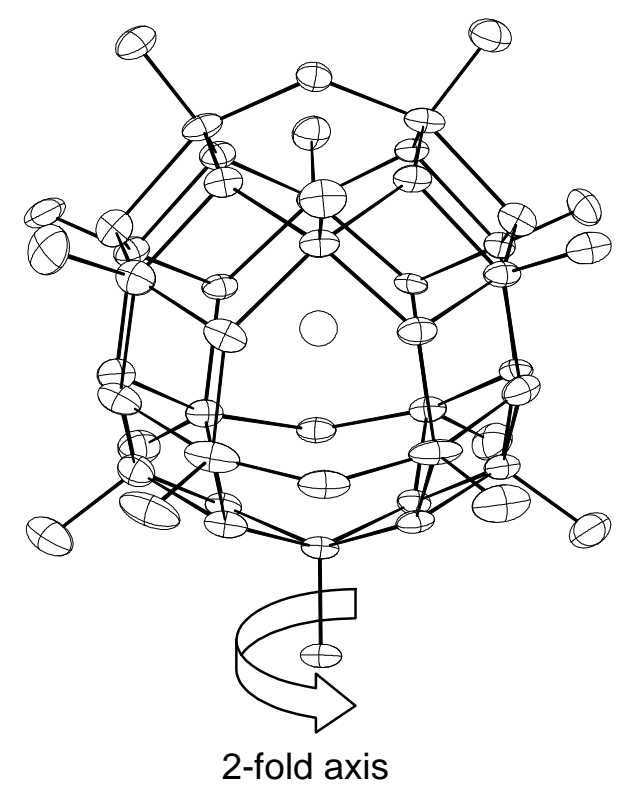

(b)

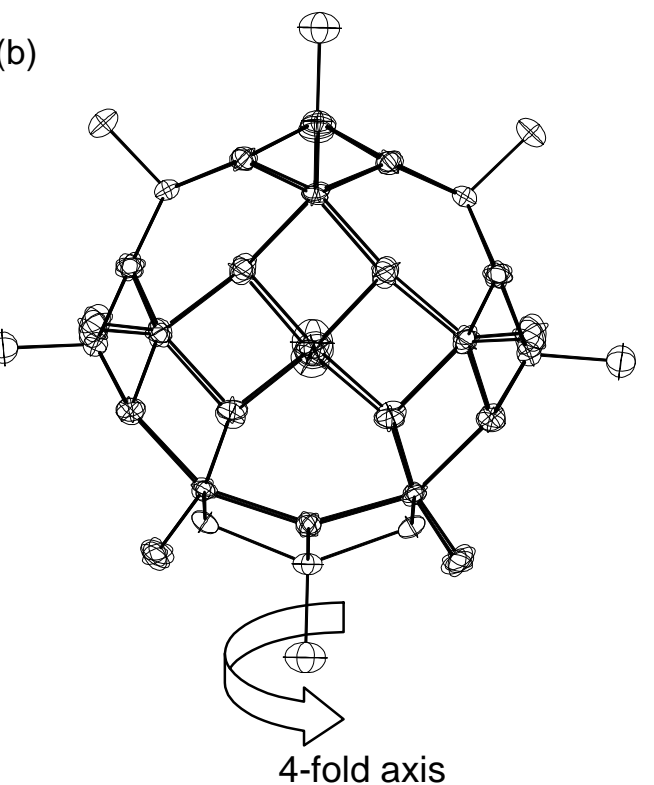

Figure 3. An ORTEP view of (a) 1 and (b) 2.

tained from single crystal analysis. DTA of the two solids showed an endothermic peak at lower temperature due to water molecules and other at higher temperature due to the removal of organic templates in correspondence with TG analysis. FTIR spectrum of 1 showed strong bands at 965, 888, 844, 721 and $665 \mathrm{~cm}^{-1}$ due to $\mathrm{V}-\mathrm{O}$ symmetric stretching and $\mathrm{V}-\mathrm{O}-$ $\mathrm{V}$ anti-symmetric stretching vibrational modes. ${ }^{13}$ Bands in the $1626-1099 \mathrm{~cm}^{-1}$ region are attributed to extending vibrations of en groups. ${ }^{14}$ FTIR spectrum of 2 exhibited similar characteristic peaks for oxovanadate network. The strong bands at 981, 769, 732 and $660 \mathrm{~cm}^{-1}$ are ascribed to $\mathrm{V}-\mathrm{O}-\mathrm{V}$ symmetric stretching and $\mathrm{V}-\mathrm{O}-\mathrm{V}$ anti-symmetric stretching vibrational modes. ${ }^{13}$ Bands in the range of 1632 $1017 \mathrm{~cm}^{-1}$ are characteristic of $\mathrm{C}-\mathrm{C}$ and $\mathrm{C}-\mathrm{N}$ bonds of $p n$ groups. ${ }^{14}$

\subsection{Crystal structure of $\mathbf{1}$}

The cluster anion, $\left[\mathrm{Cl} \subset \mathrm{V}_{15} \mathrm{O}_{36}\right]^{8-}$ in $\mathbf{1}$ is closely related to those found in alkali vanadium oxide/halide systems described by Müller et $a l^{15,16}$ with idealized $C_{2}$ symmetry (figure $3 \mathrm{a}$ ). The cluster $\left[\mathrm{Cl} \subset \mathrm{V}_{15} \mathrm{O}_{36}\right]^{8-}$ is made of a nearly spherical oxovanadium shell built up from fifteen $\mathrm{VO}_{5}$ distorted square pyramids 
that share edges and corners through three $\mu 2$ - and eighteen $\mu 3$-oxygen atoms, respectively. The $\mathrm{V}$ atoms are arranged at the surface of a sphere with a radius $\sim 3.6 \AA$ from the central $\mathrm{Cl}^{-}$. The fifteen apical oxygens of the $\mathrm{VO}_{5}$ square pyramids point out of the cage (figure 3a). In the distorted $\left\{\mathrm{VO}_{5}\right\}$ square pyramid, $\mathrm{V}-\mathrm{O}_{b}$ lengths are in the range 1.782(6)-2.036(6) $\AA$, $\mathrm{V}-\mathrm{O}_{t}$ lengths $1.605(6)-1.639(6) \AA$, and bond angles of $\mathrm{O}-\mathrm{V}-\mathrm{O}$ vary from $78 \cdot 4(2)$ to $154 \cdot 7(2)^{\circ}$. The chloride anion adopts a tricosahedral coordination, implying 23 oxygen atoms with the $\mathrm{Cl}-\mathrm{O}$ distance $\sim 3.4 \AA$, from oxygen atoms of the basal plane of the square pyramids.

Four counter cations, $\left[\mathrm{Cu}(e n)_{2}\right]^{2+}$, present in the medium, coordinate with $\mathrm{V}_{15}$ cluster anions on one side to form infinite chains (figure $4 \mathrm{a}$ ) with $\mathrm{Cu}-\mathrm{O}$ distances of 2.481(1) ^̊ during self-assembly (figure 4b). The 1D chains are further linked via a weaker $\mathrm{Cu}-\mathrm{O}$ bond $(\sim 2 \cdot 606(1) \AA)$ to form a three-dimensional network (figure 5). In addition, 1 also exhibits hydrogen-bonding interactions between the amine nitrogens and terminal and bridging oxo groups of the cluster along with the water molecules that occur as space fillers. Crystal structure analysis shows that one of the copper ethylenediamine complex rings has rather high thermal parameters. This feature arises probably from some kind of dynamic disorder because of the high volume cell and large number of atoms. Since no special problems for locating atoms were encountered, it is concluded that the structural determination is reasonably correct. Bond valence sums ${ }^{17}$ (BVS) of $\mathrm{V}_{15}$ suggest delocalisation of charge over all the vanadium centres (table 2). On the basis of single crystal structure, bond valence sums and thermal analysis, we derived the composition of $\mathbf{1}$ as $\left\{\mathrm{Cu}(\text { en })_{2}\right\}_{4}\left[\mathrm{Cl} \subset \mathrm{V}_{15} \mathrm{O}_{36}\right] \cdot 12 \mathrm{H}_{2} \mathrm{O}$.

\subsection{Crystal structure of $\mathbf{2}$}

The $\left\{\mathrm{V}_{18} \mathrm{O}_{42}\right\}$ shell in $\mathbf{2}$ is essentially similar to $\mathrm{Cs}_{12}\left[\left(\mathrm{H}_{2} \mathrm{O} \subset \mathrm{V}^{\mathrm{IV}}{ }_{18} \mathrm{O}_{42}\right] \cdot 9 \mathrm{H}_{2} \mathrm{O}\right.$ and related compounds ${ }^{16}$

Table 2. Bond valence sums for $\mathbf{1}$

\begin{tabular}{llll}
\hline V1 & $4 \cdot 122$ & V2 & 4.520 \\
V3 & 4.655 & V4 & 4.215 \\
V5 & 4.683 & V6 & $4 \cdot 195$ \\
V7 & 4.648 & V8 & $4 \cdot 164$ \\
V9 & 4.626 & V10 & 4.849 \\
V11 & 4.722 & V12 & 4.522 \\
V13 & 4.669 & V14 & 4.762 \\
V15 & 4.694 & \\
& Average sum $=4.54$ \\
\hline
\end{tabular}

with an idealized $D_{4 d}$ symmetry (figure $3 \mathrm{~b}$ ) except that $\mathrm{Cl}^{-}$ions are trapped inside the cluster. The cluster anion $\left[\mathrm{Cl} \subset \mathrm{V}_{18} \mathrm{O}_{42}\right]{ }^{8-}$ is composed of eighteen edge-sharing $\mathrm{VO}_{5}$ square pyramids with an average $\mathrm{V}-\mathrm{V}$ distance of $\sim 3.0 \AA$. The encapsulated chloride

(a)

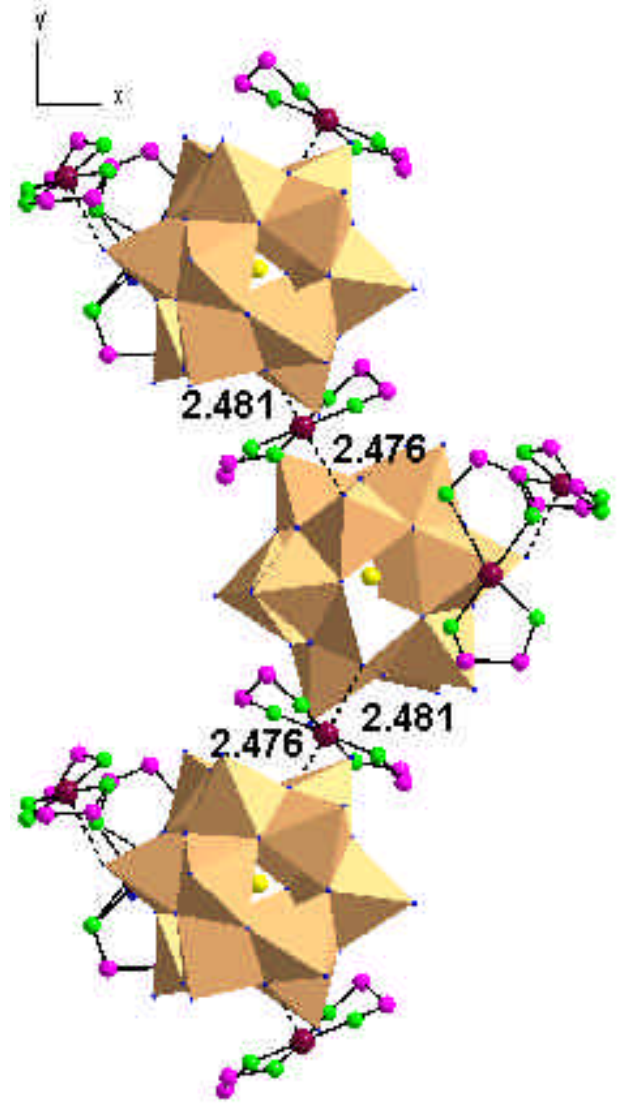

(b)

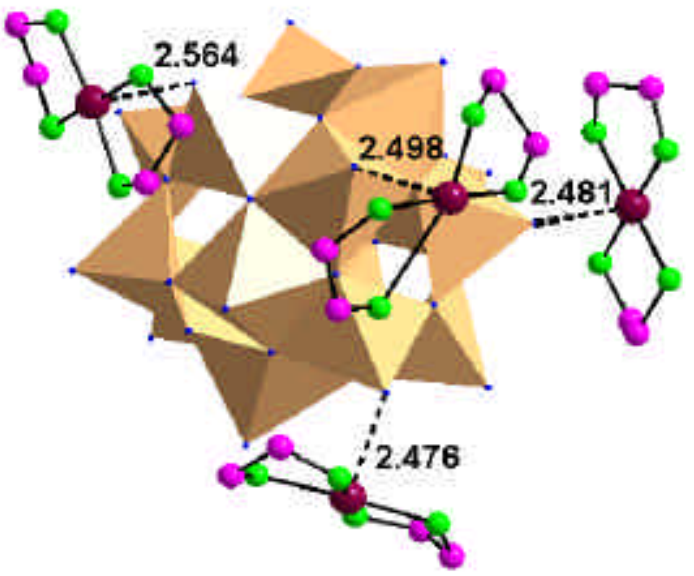

Figure 4. (a) $\left[\mathrm{Cu}(e n)_{2}\right]^{2+}$ and $\mathrm{V}_{15}$ forming $1 \mathrm{D}$ chains along $z$-axis in 1. (b) Each $\mathrm{V}_{15}$ cluster in 1D chain is enveloped by four $\left[\mathrm{Cu}(e n)_{2}\right]^{2+}$ with short $\mathrm{Cu}-\mathrm{O}$ distance $(\sim 2 \cdot 5 \AA)$. 


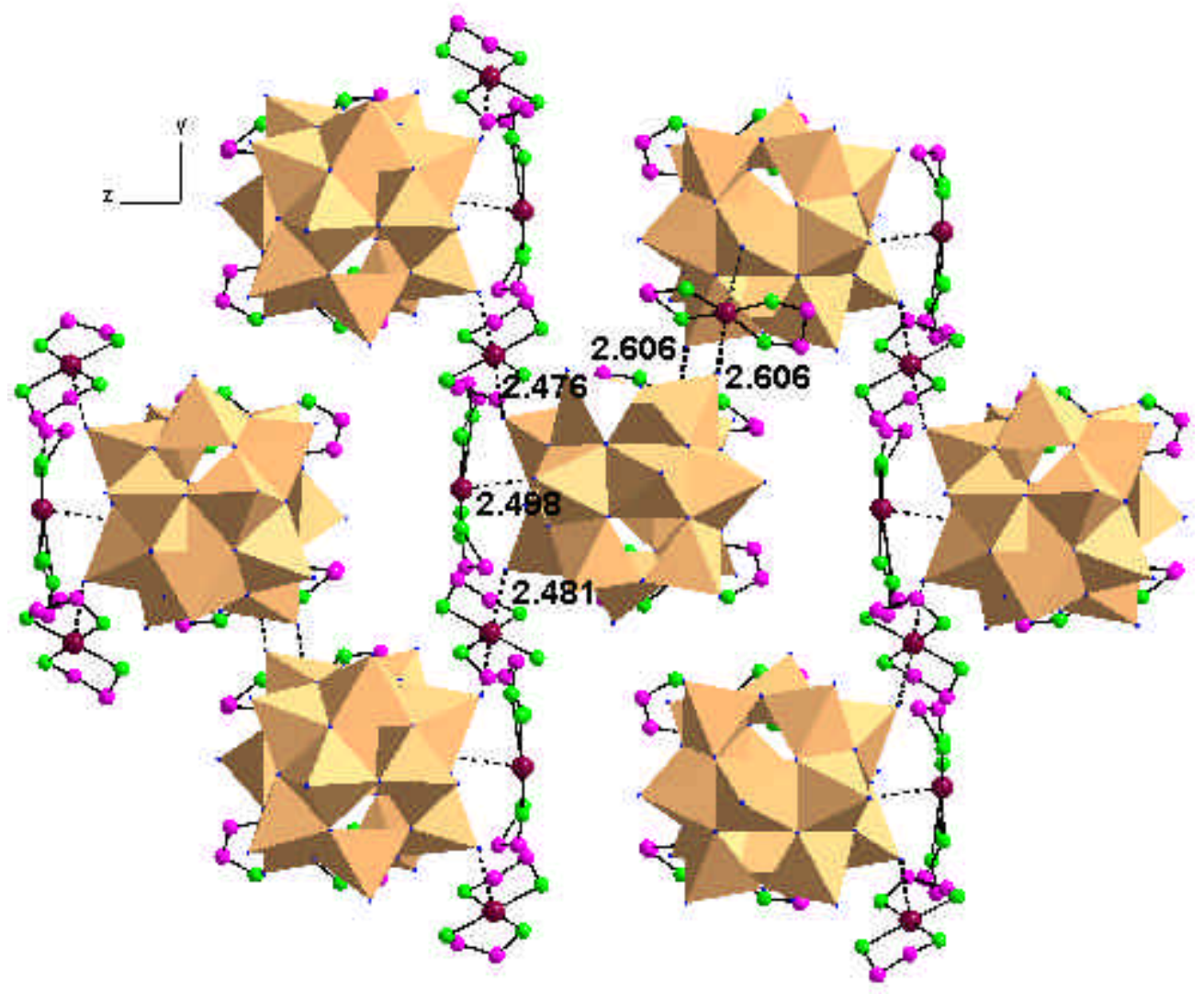

Figure 5. Interaction of $1 \mathrm{D}$ chains on the $b c$-plane through longer $\mathrm{Cu}-\mathrm{O}$ distances $(\sim 2 \cdot 6 \AA)$. (water molecules are not shown, for clarity).

Table 3. Bond valence sums for 2

\begin{tabular}{lr}
\hline V1 & 4.399 \\
V2 & 4.498 \\
V3 & 4.555 \\
& Average sum $=4.48$ \\
\hline
\end{tabular}

ion in the shell has no appreciable interaction with the shell framework. The average distance of this chloride ion from the $\mathrm{V}$ atoms of the shell is $\sim 3.78 \AA$ All the $\mathrm{VO}_{5}$ units in $\mathbf{2}$ have a terminal oxo group and four $\mu_{3}$-oxygen atoms. Each $V_{18}$ cluster is enveloped by eight $\left[\mathrm{Cu}(p n)_{2}\right]^{2+}$ cations connected through coordinate bonding (figure 6) to form a three-dimensional network with water molecules occupying interstitial spaces (figure 7).

$\mathrm{V}-\mathrm{O}$ distances and BVS calculations ${ }^{17}$ (table 3 ) indicate that the oxygen atoms in $\left[\mathrm{Cl} \subset \mathrm{V}_{18} \mathrm{O}_{42}\right]^{8-}$ are not protonated. 2 exhibits hydrogen-bonding interactions between the amine nitrogens and terminal and bridging oxo groups of the clusters along with water molecules. The cell parameters of $\mathbf{2}$ seem to be similar to those reported recently in the literature. ${ }^{18,19}$ On the basis of single crystal structure, bond valence sums and thermal analysis, we derived the composition of 2 as $\left\{\mathrm{Cu}(p n)_{2}\right\}_{4}\left[\mathrm{Cl} \subset \mathrm{V}_{18} \mathrm{O}_{42}\right] \cdot 12 \mathrm{H}_{2} \mathrm{O}$.

\subsection{Magnetic properties}

Magnetic properties of $\mathbf{1}$ and $\mathbf{2}$ were investigated between 300 and $5 \mathrm{~K}$. Figures 8 and 9 show $\chi^{-1}$ versus $T$ and $\chi$. $T$ versus $T$ in the low temperature region. The linear portions of the plots have been fitted to the Curie-Weiss relation yielding the Weiss constants of $-11 \mathrm{~K}$ and $-6 \mathrm{~K}$ for the structures 1 and 2 respectively. The negative values of the Weiss constant indicate that the precursor exchange interactions are dominantly anti-ferromagnetic, although no long-range ordering was observed down to $5 \mathrm{~K}$ in either of the samples. The effective magnetic moments calculated for both 1 and 2 were $\sim 4.4$ and 5.8 BM respectively corresponding to $\sim 6$ and $\sim 11$ unpaired electrons per formula unit. However, the observed number of unpaired electrons is smaller than expected based on four copper ions and fifty percent of $\mathrm{V}^{4+}$ population in the vanadium clusters as estimated 
from bond valence sums. It is interesting to note that in contrast to the lower $\chi . T(\sim 1-2 \mathrm{BM})$ values observed by Müller et $a l^{20}$ for mixed-valent $\mathrm{V}_{18}$ clusters containing similar vanadium (IV) population, in the present samples, the $d$ electrons seem more localized. Further studies including e.s.r. and neutron diffraction are currently underway to address this issue.

(a)

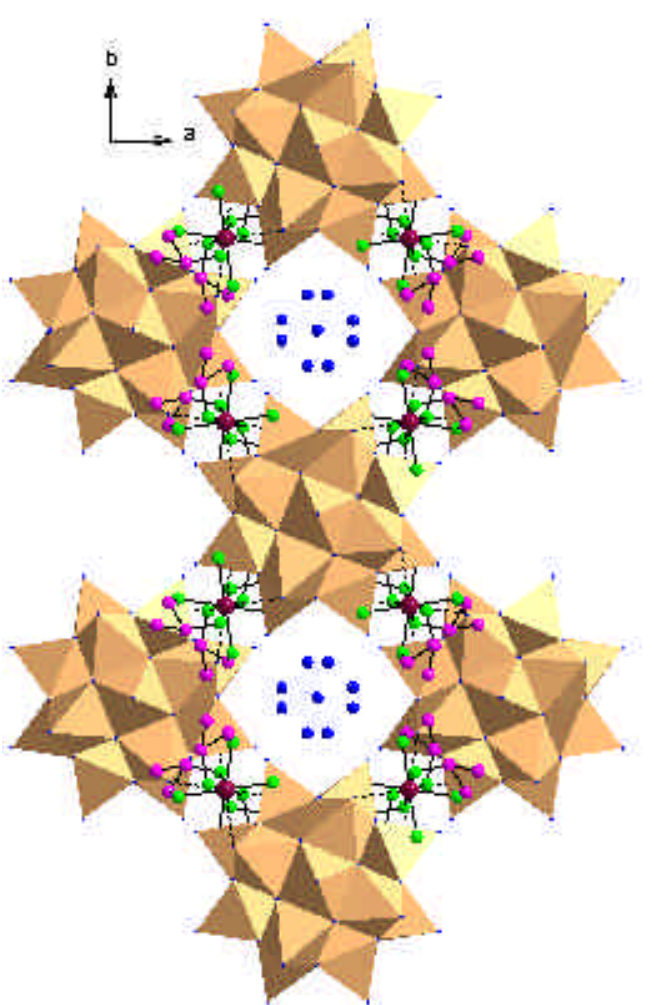

(b)

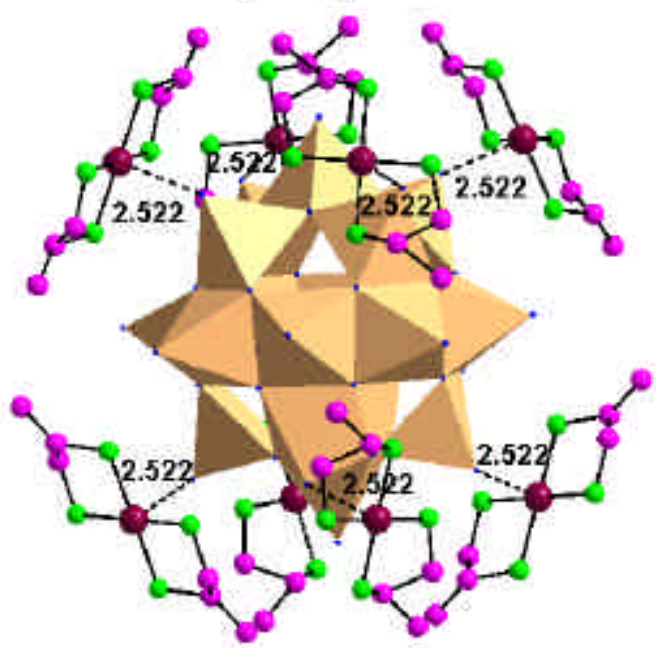

Figure 6. (a) Packing arrangement of three-dimensional network of $\mathrm{V}_{18}$ in $\mathbf{2}$ viewed along the $z$-axis. Tetragonal cavities show the presence of water molecules. (b) A supramolecular assembly of $\mathrm{V}_{18}$ with eight symmetrically coordinating $\left[\mathrm{Cu}(p n)_{2}\right]^{2+}$ complexes.

\subsection{Chemistry of formation of high nuclearity polyoxovanadates}

An examination of all $\mathrm{V}_{15}$ and $\mathrm{V}_{18}$ clusters reported in the literature suggest that anions or water molecules clearly dictate the formation of this cluster especially when crystallisation is carried out from solutions containing substantial amounts of lower valent vanadium. ${ }^{16,20}$ There exist no example of $V_{15}$ clusters wherein all the vanadium occurs in the +4 oxidation state. $\mathrm{V}_{18}$ clusters do occur with all vanadium in the +4 oxidation state but only in the presence of the alkali metals, $\mathrm{Rb}, \mathrm{Cs}$ and $\mathrm{K}$, as counter cations. ${ }^{20}$ In fact, neither of these clusters is stabilised in the presence of sodium ions; decavanadates and Keggin clusters dominate reactions containing hydrated sodium ions. In the presence of larger counter cations such as tetra alkyl ammonium or metal complexes, their charge and size decides the overall charge on the anions and the clusters are invariably mixed-valent. ${ }^{7,21}$ Copper complexes present in the solution readily coordinate with these clusters and the supramolecular assemblies thus formed dictate the crystal packing of the final solid. While $\left[\mathrm{Cu}(e n)_{2}\right]^{2+}$ is known only in $\mathbf{1}\left(\mathrm{V}_{15}\right.$ cluster $)$ as a counter cation, $\left[\mathrm{Cu}(p n)_{2}\right]^{2+}$ occurred as a counter cation in many solids: $\left\{\mathrm{Cu}(p n)_{2}\right\}_{3}\left[\mathrm{Cl} \subset \mathrm{V}_{15} \mathrm{O}_{36}\right]$. $2 \cdot 5 \mathrm{H}_{2} \mathrm{O},{ }^{22} \quad\left[\left\{\mathrm{Cu}(p n)_{2}\right\}_{7}\left\{\left(\mathrm{H}_{2} \mathrm{O}\right)_{2} \subset \mathrm{V}_{16} \mathrm{O}_{38}\right] \cdot 4 \mathrm{H}_{2} \mathrm{O},{ }^{23}\right.$ $\left\{\mathrm{Cu}(p n)_{2}\right\}\left[\mathrm{Cl} \subset \mathrm{V}_{16} \mathrm{O}_{38}\right] \cdot 3 \cdot 5 \mathrm{H}_{2} \mathrm{O},{ }^{24}\left\{\mathrm{Cu}(p n)_{2}\right\}_{4}\left[\left(\mathrm{H}_{2} \mathrm{O}\right) \subset\right.$ $\left.\mathrm{V}_{18} \mathrm{O}_{42}\right] \cdot 8 \mathrm{H}_{2} \mathrm{O},{ }^{18}\left\{\mathrm{Cu}(p n)_{2}\right\}_{4}\left[\mathrm{Cl} \subset \mathrm{H}_{5} \mathrm{~V}_{18} \mathrm{O}_{42}\right] \cdot 8 \mathrm{H}_{2} \mathrm{O},{ }^{19}$ and $\left\{\mathrm{Cu}(p n)_{2}\right\}_{4}\left[\mathrm{Cl} \subset \mathrm{V}_{18} \mathrm{O}_{42}\right] \cdot 12 \mathrm{H}_{2} \mathrm{O}$. In addition, the way different copper complexes coordinate with the anion, decides the overall symmetry of the unit cell. The high symmetry reflected in the crystal packing of 2 probably suggests that nucleation is induced by the symmetry of the supramolecular assembly.

Another interesting observation that emerges out of this work is that whenever crystallisation is carried out under slow evaporation conditions, bi-capped Keggin clusters are favoured if the solution does not contain sufficient concentration of lower-valent vanadium. ${ }^{5,13,25}$ Formation of $\mathrm{V}_{15}$ and $\mathrm{V}_{18}$ under our reaction conditions was due to the reduction of vanadium species by the organic amines such as en and $p n$ under hydrothermal condition. We intentionally did not employ any vanadium metal or lower valent vanadium precursors in our reactions. On the basis of the present work and past experience, ${ }^{5,6,25-27}$ we infer that in many cases $\mathrm{pH}$ and concentration of lower-valent vanadium are the primary factors responsible for the occurrence of a particular POV cluster-based solid; in many cases the organic cations 


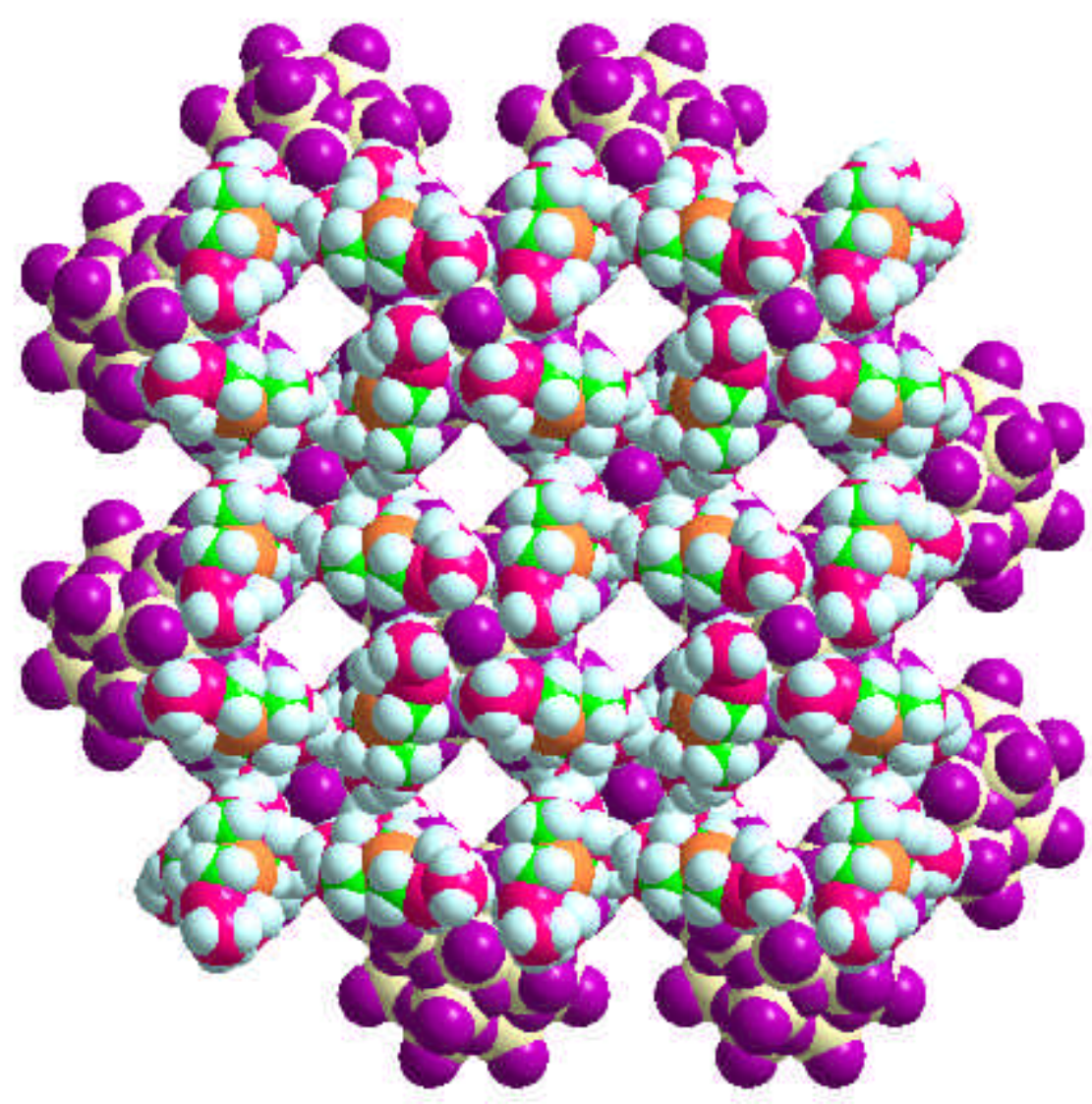

Figure 7. CPK representation of $\mathbf{2}$ (water molecules are not shown, for clarity).

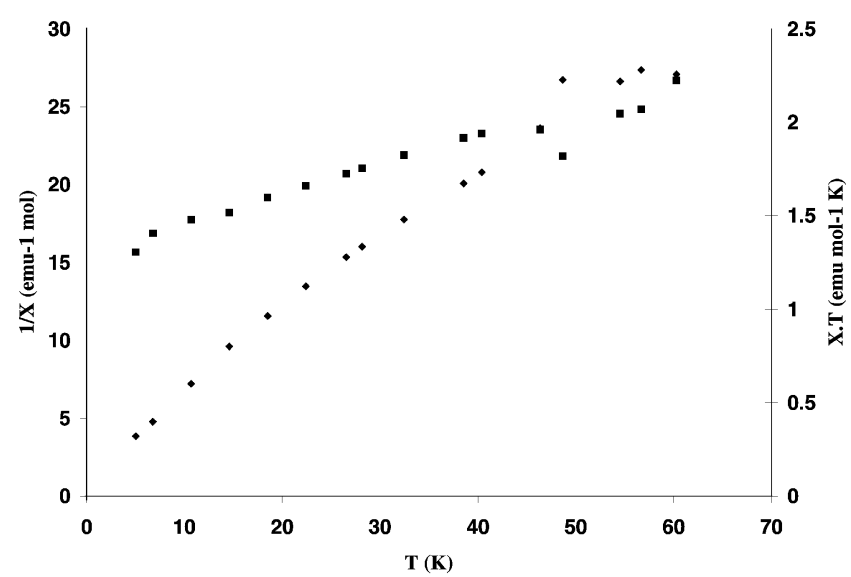

Figure 8. $\chi^{-1}$ vs $T(\bullet)$ and $\chi . T$ vs $T(\boldsymbol{\square})$ of 1 in the 5$60 \mathrm{~K}$ temperature range.

occur as spectator counter-cations. Hydrothermal conditions assist the reduction of vanadates by organic amines to the lower-valent state. In addition, it provides better solubility of reactants and formation of good crystals.

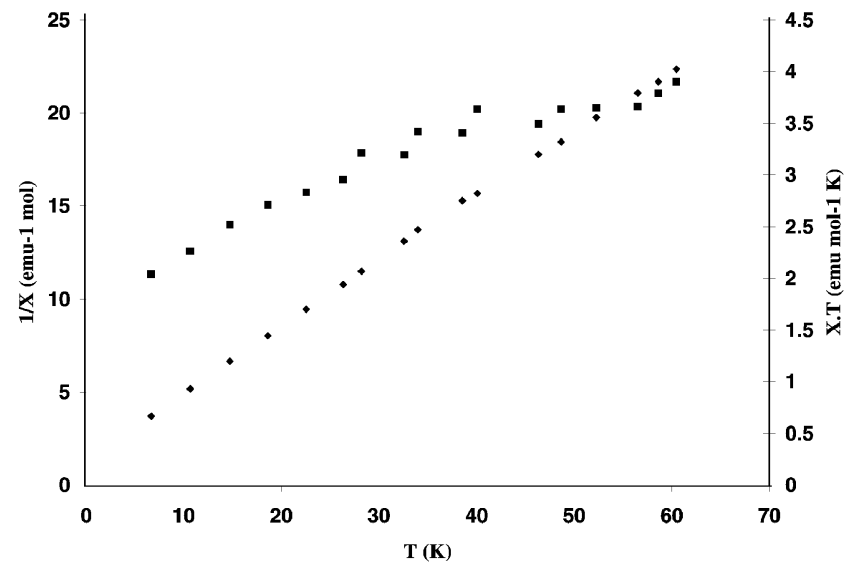

Figure 9. $\chi^{-1}$ vs $T(\diamond)$ and $\chi . T$ vs $T(\boldsymbol{\square})$ of 2 in the 5$60 \mathrm{~K}$ temperature range.

\section{Conclusions}

High nuclearity POV-based solids reported here crystallise from aqueous solution containing lowervalent vanadium species but are essentially driven 
by chloride ions. The size and nature of the counter cations play a secondary role in stabilising such clusters. Hydrothermal medium is effective in solubilising reactants that are otherwise insoluble in aqueous solution and promoting reduction of vanadium species with organic amines. The coordinating ability of the counter cation with a particular POV cluster dictates the crystal packing of these hybrid solids. Hydrothermal chemistry will be more attractive for materials syntheses if a rational strategy is evolved rather than employing a cocktail of arbitrary reactants and reaction conditions.

\section{Acknowledgments}

JT acknowledges CSIR for a fellowship. AR acknowledges DST for financial support and DST-IRHPA and DST-FIST for the powder and single crystal Xray diffraction facility to Department of Chemistry, IIT, Delhi. AR, KVR and SEL express their respect and admiration to Prof J Gopalakrishnan whose contributions have enriched our understanding of the fascinating chemistry of inorganic solids.

\section{References}

1. Coronado E and Gomez-Garcia C J 1998 Chem. Rev. 98273

2. Pope M T 1983 Heteropoly and isopoly oxometalates (Berlin: Springer)

3. Pope M T and Müller A 1994 In Polyoxometalates: From platonic solids to anti-retroviral activity (Dordrect: Kluwer)

4. Müller A, Peters F, Pope M T and Gatteschi D 1998 Chem. Rev. 98239

5. Duraisami T, Ojha N, Ramanan A and Vittal J J 1999 Chem. Mater. 112339

6. Duraisami T, Ramanan A and Vittal J J 2001 Cryst. Eng. 3237
7. Müller A, Rohlfing R, Krickemeyer E and Bogge H 1993 Angew. Chem., Int. Ed. Engl. 32909

8. Suber L, Bonamico M and Fares V 1997 Inorg. Chem. 362030

9. Khan M I, Ayesh S, Doedens R J, Yuc M and O'Connor C J 2005 Chem. Commun. 4658

10. Hayashi Y, Fukuyama K, Takatera T and Uehara A 2000 Chem. Lett. 770

11. Hayashi Y, Miyakoshi N, Shinguchi T and Uehara A 2001 Chem. Lett. 170

12. Pavani K and Ramanan A 2005 Eur. J. Inorg. Chem. 153080

13. Sharma S, Ramanan A and Vittal J J 2001 Prod. Indian Acad. Sci. (Chem. Sci.) 113621

14. Nakamoto K 1978 Infrared and Raman spectra of inorganic and coordination compounds (New York: John Wiley \& Sons)

15. Müller A, Krickemeyer E, Penk M, Walberg H J and Bogge H 1987 Angew. Chem. Int. Ed. Engl. 261045

16. Müller A, Krickemeyer E, Penk M, Rohlfing R, Armatage A and Bogge H 1991 Angew. Chem. Int. Ed. Engl. 301674

17. Brown I D and Altermatt D 1985 Acta Crystallogr. B41 244

18. Lin B Z and Liu S X 2002 Gaodeng Xuexiao Huaxue Xuebao 23535

19. Cui X B, Zheng S T, Ding L, Ding H and Yang G Y 2003 Jiegou Hиахие 22491

20. Müller A, Sessoli R, Krickemeyer E, Bogge H, Meyer J, Gatteschi D, Pardi L, Westphal J, Hovemeier K, Rohlfing R, Doring J, Hellweg F, Beugholt C and Schmidtmann M 1997 Inorg. Chem. 365239

21. Khan M I 2000 J. Solid State Chem. 152105

22. DeBord J R D, Haushalter R C, Meyer L M, Rose D $\mathrm{J}$, Zapf $\mathrm{P}$ and Zubieta J 1997 J. Inorg. Chim. Acta 256165

23. Lin B and Liu S 2002 Chem. Commun. 2126

24. Cui X, Zheng S, Sun Y and Yang G 2004 Chem. Res. Chin. Univ. 20266

25. Pavani K, Upreti S and Ramanan A 2006 J. Chem. Sci. (accepted)

26. Sharma S, Ramanan A and Jansen M 2004 Solid State Ionics 17093

27. Sharma S, Ramanan A, Zavalij P Y and Whittingham M S 2002 Cryst. Eng. Comm. 4601 